\section{Brasileiras por trás das câmeras do cinema}

\section{Brazilian women behind the cinema cameras}

\section{Amadeu Weinmann}

Universidade Federal do Rio Grande do Sul. Instituto de Psicologia.

\section{Barbara Marques}

Universidade Federal do Rio Grande do Sul. Instituto de Psicologia.

\section{RESUMO}

O artigo pesquisa a presença de mulheres atrás das câmeras no cinema nacional. Para tal, reporta-se a algumas importantes teóricas feministas do cinema, apresenta algumas pioneiras do cinema (tanto nacional, quanto internacional) e comenta alguns filmes brasileiros dirigidos por mulheres. Nesse percurso, procura salientar os efeitos subjetivantes dessa filmografia.

\section{ABSTRACT}

The article searches for the female presence behind the cameras in Brazilian cinema. For this purpose, it reports to some important feminist authors of the cinema, introduces some cinema pioneers (both national and international) and comment on some Brazilian movies directed by women. On this path, it seeks the highlight of the subjective effects of this filmography.

PALAVRAS-CHAVE: cinema brasileiro, KEYWORDS: Brazilian cinema, women, mulheres, gênero, psicanálise, gender, psychoanalysis, patriarchy. patriarcado.
Admirava a liberdade que tinham para a expressão da sensibilidade, achava que era como uma permissão para ter a alma à solta, autorizada a manifestar-se pela beleza ou pelo espanto de cada coisa. Estava autorizada à sensibilidade que fazia da vida uma travessia mais intensa. As mulheres, pensava ele, eram mais intensas (Valter Hugo Mãe, O filho de mil homens).

\section{POR QUE O CINEMA?}

Criado pelos irmãos Lumière, no final do século XIX, e, mais tarde, transformado em ferramenta de projeção para encenações ficcionais, a francesa Alice Guy-Blaché aparece como pioneira dirigindo, produzindo e escrevendo seu primeiro filme, "La Fée aux choux" (em tradução literal, A fada do repolho), em 1896, de acordo com McMahan (2002). Apesar de Guy Blaché ser a primeira diretora da história, de acordo com muitos historiadores do cinema, há aqueles que afirmam que seu primeiro filme foi feito alguns meses depois do primeiro de Georges Méliès, ou ignoram ou diminuem sua importância para a construção do cinema como conhecemos. A despeito dessas contradições, a presença de uma mulher na estruturação do cinema como difusor de narrativas de ficção foi de suma importância, desde o princípio.

Sendo o cinema um ritual de "projeção-identificação" (ASTRE, 1976), Mário e Diana Corso (2011, p. 24) afirmam: "a ficção não é apenas uma forma de diversão, é também o veículo através do qual se estabelece um cânone imaginário utilizado para elaborar algum aspecto da nossa subjetividade ou realidade social". Nesse ritual, tanto projetamos elementos da nossa subjetividade e do contexto em que estamos inseridos (e que podem mudar, na medida em que estamos em constante transformação), como introjetamos aspectos que cremos ser relevantes da história que é contada. Se o inconsciente - estruturado como uma linguagem - é o discurso do Outro (LACAN, 1998), no sentido de que nos constituímos em torno dos discursos 
dominantes de uma cultura, não é exagero afirmar que o cinema também constrói modos de ser e estar no laço social, visto que, antes de falar, somos falados a partir da cultura em que estamos inseridos, da qual o cinema faz parte.

De acordo com Mulvey (2008, p. 437), a teoria psicanalítica - falocêntrica, surgida no berço do patriarcado burguês - é "um instrumento político que demonstra o modo pelo qual o inconsciente da sociedade patriarcal estruturou o cinema". A mulher do inconsciente patriarcal simboliza o temor da castração, ao mesmo tempo em que introduz o infans na ordem simbólica (no mundo da linguagem). Na ordem falocêntrica, a linguagem se organiza em torno da falta do falo. Se o inconsciente se estrutura como uma linguagem, como propõe Lacan (2008), ocupar o lugar de locutor, isto é, de sujeito da linguagem, consiste em assumir uma posição dita masculina, em que há um apagamento da subjetividade feminina (ou do que se entende por feminino), o que se articula à opressão das mulheres no laço social. $A$ teoria psicanalítica, portanto, incide no discurso majoritário, dando a ver as nuances sociais que atravessam as produções que derivam da nossa cultura, como a linguagem cinematográfica.

Joan Scott (1989) afirma que, na teoria lacaniana, a sujeição da criança à ordem simbólica (em outras palavras, à linguagem) é constitutiva. Mediante esse assujeitamento, que implica assumir uma posição diante do falo - ter ou não ter, eis a questão colocada pelo complexo de castração -, seria construída a identidade de gênero. Nessa perspectiva, Teresa de Lauretis (1994) propõe que o cinema, como linguagem, produz e reproduz modos de subjetivação do masculino e do feminino, refletindo seu contexto cultural.

Para a socióloga brasileira Heleieth Saffioti(2015), o patriarcado opera dando cobertura a uma estrutura de poder que mantém as mulheres subalternas aos homens em todas as áreas de convivência humana, em que podemos incluir o cinema. A autora ainda 94 vai dizer que o patriarcado é produto de um sistema ideológico que se implantou nos últimos milênios na raiz de diversas instituições sociais - tais como educação, família, religião -, atravessando todos os espaços da sociedade, em uma hierarquia de primazia masculina.

Nesse sentido, o cinema evidencia as contradições sociais ao se transformar em mecanismo de representação social e de produção de significados, entre eles, os que remetem às relações de gênero e às diferenças entre os sexos, interferindo no processo de socialização feminina, na medida em que conduz à interiorização de comportamentos sociais que não apenas perpetuam, como engendram as relações de dominação. Ann Kaplan (1995, p. 46) situa o gênero melodrama como o principal vetor da representação feminina no cinema clássico, em que os personagens assumiriam basicamente os papéis de Mãe, Pai e Filho, encenando os dramas edípicos teorizados por Sigmund Freud: "os processos psicanalíticos revelam uma estética melodramática" (nesse momento, a autora cita O caso "Dora", de 1905, em que Freud teoriza sobre a histeria feminina). De acordo com Mulvey (2008), ainda que as mulheres sejam protagonistas nos melodramas familiares, elas nunca serão beneficiadas com os fatos construídos pelo enredo.

\section{O CINEMA TRADICIONAL}

Chamamos de cinema tradicional aquele que, desde o início do século XX, articulouse como uma grande indústria, o cinema hollywoodiano que, dentre outros aspectos, moldou formas de olhar, o chamado male gaze, ou o olhar masculino (MULVEY, 2008). Teresa de Lauretis (1984) afirma que o cinema hollywoodiano foi conivente com a ideologia patriarcal, originando a representação de uma mulher "cativa", isto é, presa aos estereótipos atribuídos às mulheres, como esposa, mãe, dona-de-casa, dócil e passiva. No cinema tradicional, a espectadora é convocada a assumir esse lugar - o 
que não significa que não resista a isso (KAPLAN, 1995). Lauretis (1984) sustenta que a cultura é uma área de intervenção da ideologia e, se a imagem representada da mulher é estereotipada, pode-se dizer que a construção social da mulher, operada pelas diferentes mídias, é baseada em critérios preestabelecidos socialmente e impõe uma imagem idealizada da mulher.

No cinema tradicional, houve um fenômeno conhecido como star system - a mulher como espetáculo -, em que os corpos são performativos, por apresentarem os signos do que seria considerado feminino pela cultura patriarcal e, assim, produzirem suas realidades, como afirma a filósofa Judith Butler (1999), ao propor o gênero como performance e não um atributo natural. Esse star system, iniciado ainda no cinema mudo das décadas de 1910 e 1920 (com as vamps, as it girls, as melindrosas e, mais tarde, as femme fatale do film noir), apresenta a mulher como um objeto fetiche. De acordo com Karen Horney (1991), o olhar masculino se empenharia em construir uma mulher não castrada, a fim de contornar o que há de sinistro (para os homens) na genitália feminina. A glorificação da mulher, para essa pioneira da psicanálise, teria origem não só na ânsia do homem por amor, mas em seu desejo de debelar a angústia de castração.

\section{O OLHAR É MASCULINO (?)}

Laura Mulvey (2008, p. 439) propõe: "o inconsciente (formado pela ordem dominante) estrutura as formas de ver e o prazer do olhar". O cinema narrativo clássico codificou o erótico de acordo com a linguagem da ordem patriarcal e a imagem da mulher ocupa um lugar crucial nessa erotização. A autora vincula a pulsão escópica - o impulso a olhar - ao ato de tomar outra pessoa como objeto, sujeitando-a ao controle visual. Nessa perspectiva, a mulher erotizada no cinema clássico é colocada como objeto do olhar masculino. Logo, o olhar cinematográfico, para Mulvey, é masculino. Esse olhar será do personagem, do diretor (reproduzido pela câmera) e, por processos identificatórios, do espectador. Se, por um lado, a instância narrativa, no cinema clássico, invariavelmente é assumida por homens, por outro, às mulheres é destinado o lugar de objeto da imagem. A questão da autora é como enfrentar esse inconsciente patriarcal, a fim de avançar nessa relação entre cinema e gênero, em que o primeiro produz e reproduz modos de ser para homens e mulheres. Nesse sentido, a proposta de Mulvey é um contracinema, isto é, um cinema não organizado em torno do male gaze e que possibilite à espectadora um lugar ativo, ou seja, uma identificação não masoquista.

Kaplan (1995, p. 53) questiona se o olhar é necessariamente masculino, isto é, se a mulher que ocupa a posição ativa de olhar está nesse lugar. A resposta é: "o olhar não é necessariamente masculino (literalmente), mas, para possuir e ativar o olhar, devido à nossa linguagem e à estruturação do inconsciente, é necessário que se esteja na posição masculina". A autora também analisa a ruptura com o olhar masculino e seus códigos, que "reproduziam o feminino como corpo, como locus primário da sexualidade e para o prazer visual (masculino)" (ADELMAN, 2005, p. 231). Para Kaplan, esses códigos teriam mudado antes de tudo no registro sociológico. Na medida em que o cinema expressa significações sociais, ao mesmo tempo em que as constitui, engendra-se uma tensão entre o fílmico e o extra-fílmico. Logo, a construção do discurso fílmico é tributária do inconsciente patriarcal e reproduz seus ideais; em contrapartida, ela também é permeável às possibilidades de fuga da ordem falocêntrica.

\section{CINEMA BRASILEIRO}

Um ano após a primeira exibição do cinematógrafo pelos irmãos Lumière (em Paris, em 1895), o cinema chegou ao Brasil em uma exibição de luxo na Rua do Ouvidor, 
Rio de Janeiro. Em 1897, abriu a primeira sala de cinema brasileira. A princípio, o cinema brasileiro era basicamente composto por cinejornais, retratações de crimes e curtas sobre o cotidiano. Entre 1915 e 1930, houve a isenção de taxas alfandegárias para filmes norteamericanos, reduzindo, vertiginosamente, a produção de filmes brasileiros (CLASEN, 2017).

Ao lado dessa presença maciça de filmes estadunidenses, os quais estabeleceram os ideais femininos da sociedade patriarcal, também há um processo de emancipação da mulher brasileira atrelado aos valores da sociedade norteamericana, favorecido pelo contexto da $2^{a}$ Guerra Mundial, em que as mulheres foram incentivadas a ocupar os postos vagos pela transformação dos trabalhadores em soldados; trata-se da campanha Rosie, the riveter, ilustrada por uma mulher, em roupas de operária, exibindo sua força e dizendo: we can do it. Essa relação ambígua com o cinema estadunidense não deixa de ser atravessada por relações de poder, inclusive pela desigualdade dos contextos socioculturais de ambos os países.

\section{AS MULHERES NO CINEMA BRASILEIRO}

A produção feminina no cinema brasileiro começa em 1930, com "O mistério do dominó preto", dirigido, produzido e protagonizado por Jacyra Martins da Silveira, também conhecida como Cléo de Verberena. Junto com seu marido, César Melani, Cléo vendeu suas posses para montar sua produtora, a Épica Filmes. Apesar de receber muitas críticas positivas na época, atualmente não existe mais nenhuma cópia do filme. Ela também realizou um filme falado em 1931, intitulado "Melodia da saudade", e começou a rodar "Canção do destino", que não foi concluído. A Revolução de 1932 dificultou que novos filmes fossem realizados e Cléo abandonou o cinema.Desde então, muitas brasileiras se aventuraram pelo mundo da sétima arte sem, no entanto, receberem muita visibilidade da mídia. Passando por Gilda de
Abreu, com “O ébrio" (1946), Ana Carolina, com "Mar de rosas" (1977), Norma Bengell, com "Eternamente Pagu" (1987), e Carla Camurati, que abre o cinema de retomada com "Carlota Joaquina: princesa do Brasil" (1995). No momento atual, em tempo de extinção de recursos para a cultura, ameaças à Ancine e à liberdade de expressão, temos produções como o documentário sobre travestis dos anos 1960, "Divinas divas" (2017), de Leandra Leal. Essas mulheres propõem alternativas ao olhar masculino e às representações hollywoodianas, que não contemplam formas de subjetivação das minorias, como da mulher latinoamericana não branca. No tensionamento de forças instituintes e instituídas, desdobram-se as diferenças.

Joan Scott (1989) atesta que gênero teria um significado a priori, ou seja, homens e mulheres seriam categorias sociais que simbolizariam a alteridade e, portanto, a categoria "mulher" se torna um marcador social de alguém que sofre opressão na sociedade patriarcal. Portanto, quando pensamos em cultura feita por mulheres, especialmente no cinema, encontramos uma paleta de facetas da mulher brasileira, desde as mais convencionais (mostradas em comédias românticas, principalmente) até incomuns, isto é, que fogem da branquitude e da heteronormatividade binária vigente. Grande parte dos filmes são repletos de críticas sociais sobre os papéis de gênero, de classe e de etnia. Por isso, os filmes das brasileiras têm um papel importante na formação de opinião e de subjetividade para a população, sobretudo, para as mulheres. Notamos que o lugar de fala da cineasta (se é negra ou branca, por exemplo) influencia, diretamente, no quão explícita e pungente será essa crítica social.

\section{ALGUMAS REPRESENTAÇÕES FEMININAS}

"[Dizer que um filme é um "filme de mulher"] muitas vezes aparece num contexto de ação afirmativo, o que é válido. Porém, às vezes é como se inserissem o filme 
em um gênero à parte, como se isso influenciasse a forma de filmar, quando, na verdade, cada diretora tem um olhar distinto. As mulheres não fazem parte de um movimento artístico com bases estéticas em comum para justificar que se classifique dessa forma. O que nos une é um passado em comum de institucionalização da opressão em função do gênero. A recente quebra desse padrão deve ser valorizada, não no sentido de reforçar a diferença, mas no sentido de reconhecermos que quantidade de hormônios não define talento ou vocação." (Cristiane Oliveira, diretora e roteirista de Mulher do pai, em conversa com a autora deste artigo por e-mail).

\section{“Amor maldito" (1984), de Adélia Sampaio}

"O filme branco não tem compromisso com nada, o filme negro toca na ferida "(Adélia Sampaio, diretora).

"Amor maldito" é um filme de grande relevância para o cinema nacional, apesar do pouco reconhecimento. Além de ser o primeiro longa-metragem dirigido por uma mulher negra - Adélia Sampaio -, o filme aborda a relação homossexual entre duas mulheres, Fernanda (Monique Lafond) e Sueli (Wilma Dias), na época da ditadura militar e de retrocessos conservadores, onde a arte, de uma forma geral, e o cinema em particular, tende a ser censurado e, no limite, criminalizado. Ainda muito atual, o filme aborda o preconceito aos homossexuais, o machismo atrelado à religião evangélica a serviço da condenação da mulher e da sua sexualidade.

A diretora sempre reforça em entrevistas (disponíveis no YouTube) as dificuldades de financiamento, lançamento e distribuição do filme. O financiamento foi feito por uma mulher, engenheira, que se interessou pela história do filme. Já o lançamento e a distribuição só foram possíveis quando a película foi classificada como pornochanchada, o que nos dá pistas de como a homossexualidade (especialmente das lésbicas) é concebida no panorama da sociedade brasileira - erotizada e marginalizada. Mesmo assim, a diretora concebe uma história com críticas sociais pungentes que acompanham quem o assiste por muito tempo. É por isso que ela diz que o cinema negro deve ser necessariamente implicado, uma mulher negra fazer cinema, que é elitizado, em si já se configura um ato de resistência.

Para além das polêmicas envolvendo a produção e o assunto do filme, é importante ressaltar que esse é o único longa-metragem brasileiro, que encontramos em nossa pesquisa, dirigido por uma mulher negra. Estudos do GEMAA (Grupo de Estudos Multidisciplinar da Ação Afirmativa) apontam para a exclusão de mulheres negras no cinema nacional. A cultura de um país com raízes escravocratas, onde o racismo é estrutural, reproduz e internaliza valores brancos ocidentais, atuando como uma via de dominação. As políticas de branqueamento e de eugenização da população brasileira no século XIX visava trazer imigrantes europeus para higienizar não somente a população, mas também a moral e a cultura do país (Berth, 2018). Os escravos foram libertos, mas não houve políticas públicas para inseri-los na sociedade, tornando-se uma população marginalizada.

Além disso, é necessário ressaltar qual é o espaço de fala que é dado à mulher negra, não apenas no laço social como um todo, mas também nos espaços ditos feministas (afinal, se nesses espaços se exclui, sistematicamente, algumas mulheres, não podemos chamar tais movimentos de feminismo). Sandra Azerêdo (apud CANTO, 2009) problematiza o gênero como uma das formas que relações de opressão assumem numa sociedade capitalista, racista e colonialista. Canto $(2009$, p. 65) cita Haraway:

As mulheres negras foram simultaneamente constituídas, racial e sexualmente como fêmea marcada (animal, sexualizada e sem direitos), mas não como mulher (humana, esposa potencial, conduto para o nome do pai) - numa instituição 
específica à escravidão, que as excluía da "cultura" definida como a circulação dos signos através do sistema de casamento.

No Brasil, a inserção da mulher negra no cinema tem sido mais proeminente em festivais específicos e através do YouTube. Ressalto "Lápis de cor" (2014), de Larissa Fulana de Tal, que evidencia as consequências do racismo, estrutural em nossa sociedade, na autoestima de crianças negras brasileiras. Em entrevistas feitas em uma escola primária, as crianças relatam o bullying que sofrem por causa da cor da pele e do cabelo, e fazem desenhos de como são e de como gostariam de ser a maioria delas desenha crianças brancas de olhos claros. "O dia de Jerusa" (2014), da cineasta baiana Viviane Ferreira, retrata com muita sensibilidade a solidão da mulher negra, contado a partir do ponto de vista da jovem agente de pesquisa, Sílvia (Débora Marçal). À medida em que Jerusa (interpretada, lindamente, por Léa Garcia) responde a suas perguntas sobre uma marca de sabão em pó, também vai lhe contar sua história de vida, marcada por dificuldades que apenas uma mulher negra em um país de tradição escravocrata conhece; nesse ínterim, descobrimos que a narrativa se passa no dia de seu aniversário de 77 anos. Viviane Ferreira, em "Encontro de cinema" (2016), do Itaú Cultural, afirma que faz cinema por uma questão política, entendendo que o cinema é uma arte que constrói, simbolicamente, uma narrativa que dialoga com as pessoas de um lugar menos violento, onde não é preciso sangrar, objetivamente, e que se consegue entregar um filme que pode influenciar alguém pelo resto da vida. Para ela, o cinema, além de ferramenta de expressão artística, também opera como ferramenta política. Ela segue falando de como essas narrativas são criadas a partir de um "espelho fractal", que se fala a partir de si e, portanto, os temas que perpassam suas histórias vão discorrer sobre a subjetividade da população negra no mundo.

\section{MAIS REPRESENTAÇÕES COM O RECORTE DE COR...}

Além da mulher preta, brasileiras de outras etnias também buscam o cinema para contar suas histórias. De origem asiática, Tizuka Yamazaki - filha e neta de japoneses - é o nome mais proeminente. Tendo feito muitos filmes comerciais e trabalhado com grandes nomes, como Nelson Pereira dos Santos e Glauber Rocha, Tizuka tem sua estreia como diretora e roteirista em 1980, com o filme "Gaijin: caminhos da liberdade", que fala sobre as dificuldades enfrentadas por colonos japoneses que vieram ao Brasil para trabalhar nas fazendas de café em condições similares à escravidão. A obra foi premiada tanto no Brasil, recebendo prêmio de melhor filme no festival de Gramado, quanto no exterior, recebendo menção especial do júri no Festival de Cannes. Em 1983, a cineasta dirigiu outro sucesso, "Parahyba mulher macho", sobre a poetisa feminista paraibana Anaíde Beiriz. A questão de mulheres de origem asiática é que não é dado que existe racismo contra elas, como acontece com mulheres de outras etnias. Evidentemente, há uma diferença em como o racismo opera para as diferentes etnias; no caso da mulher asiática, além do apagamento e da fetichização (também presente para as mulheres negras), há uma estereotipização de como o Ocidente as enxerga, que passa desde a japonesa complacente, dócil, obediente, até a árabe terrorista. A exploração ocidental enxerga a pessoa asiática como a outra, a estranha, a exótica, o que tanto desumaniza como objetifica.

Muitas produções cinematográficas (especialmente de Hollywood) fizeram o yellowface - expressão usada para designar pessoas brancas interpretando pessoas asiáticas de forma estereotipada e ofensiva, o mesmo acontecendo em casos de blackface, para negras e negros, redface, para indígenas, e brownface, para as populações do sul do continente asiático, como forma de apagamento, estereotipização e silenciamentos dessas minorias. Um dos casos mais infames é o do Sr. Yunioshi, o vizinho asiático da protagonista de "Bonequinha de luxo" (1961), 
de Blake Edwards, interpretado por Mickey Rooney como um homem chato, bobo e burro, ou, mais recentemente, o caso em que a atriz Scarlett Johansson dá vida à adaptação do mangá "Ghost in the shell" (2017), de Rupert Sanders, à protagonista Motoko Kusanagi.

Em uma crescente nos últimos anos, as mulheres indígenas também têm utilizado o cinema para contar suas histórias, preferível aos livros, por causa da tradição oral desses povos. Mais de 50 filmes foram feitos por indígenas aqui no Brasil, nos últimos anos, sendo mais de $2 / 3$ realizados por mulheres. Um dos nomes mais proeminentes é o de Graci Guarani, cineasta, fotógrafa e comunicadora, que diz no $6^{\circ}$ Cine Kurumin: festival de cinema indígena, na mesa "Ameríndias: cinema de mulheres indígenas": "o olhar do homem e da mulher é diferente, e da mulher indígena tem as suas próprias prioridades e especificidades (...) tendo a capacidade de mostrar o nosso olhar, a riqueza é maior". Ela também ressalta a importância de descolonizar as telas na webserie "Cineastas indígenas" (2018). Em seu filme "Terra nua" (2014), ela faz um relato histórico da cultura Pankararu, abordando a situação atual, comparando-a à anterior e apresentando uma visão sobre a cultura agrícola, por meio do levantamento de problemáticas e possíveis soluções. Ela ainda dirigiu "Mãos de barro" (2017) e "Tempo circular" (2018). Incentivada por seu pai, outro nome proeminente é da cineasta Pãteani Huni Kuin, que lançou o filme "Nixpu Pima: rito de passagem Huni Kuin", em 2015. Para a realização desses filmes, é preciso pedir permissão ao pajé ou ao cacique da tribo, além de ter cuidado para não filmar rituais sagrados. A maior parte dos filmes produzidos por indígenas são curtas documentais que falam dos costumes, dos problemas, da religião e da sociedade de suas respectivas tribos. As cineastas falam de como o cinema indígena é produzido coletivamente e de como o cinema brasileiro pode aprender com eles. Há também, por parte das mulheres, uma grande articulação com movimentos feministas. Infelizmente, com os cortes 104 dos últimos governos na cultura tem sido maior a dificuldade para conseguir recursos financeiros para a produção de filmes indígenas, que, para além disso, são verdadeiros documentos sociológicos desses povos e de suas culturas que foram e ainda são massacrados.

\section{“Que horas ela volta?" (2015), de Anna Muylaert}

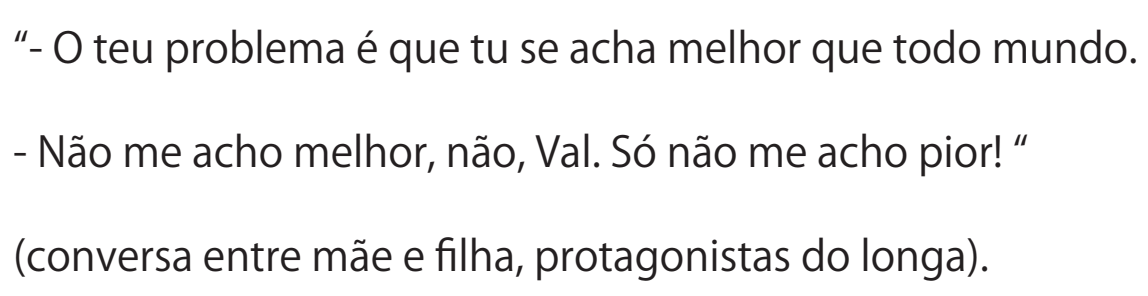

O sucesso de Anna Muylaert explora a relação desigual que empregadas domésticas vivem no país - herança de um passado escravocrata. O longa aborda as relações parentais de empregadas domésticas que cuidam e criam os filhos de suas patroas, enquanto outras pessoas cuidam dos seus.

No longa, a nordestina Val (Regina Casé) trabalha em uma mansão em São Paulo. Entre outros afazeres, assume a função materna para o filho de seus patrões, Fabinho (Michel Joelsas), enquanto sua filha, Jéssica (Camila Márdila), é criada por uma amiga em Pernambuco. Val é mais carinhosa e compreensiva com o filho dos patrões do que com a sua própria filha (Jéssica nunca a chama de mãe, mas sempre por Val). Fabinho, por sua vez, diz que Val é a sua verdadeira mãe.

As estruturas sociais se abalam quando Jéssica vai a São Paulo para prestar vestibular para arquitetura, assim como Fabinho. Apesar da culpa por ter deixado a filha para trás, mesmo que para oferecer um futuro melhor a ela, a princípio Val se incomoda com a presença da filha, por essa não aceitar a separação de classes, na casa, e por enxergar as contradições existentes na relação patrões-empregada e o preconceito velado com a condição "inferior" imposta à posição social de sua mãe.

Ainda que não consiga fugir de alguns estereótipos, talvez pelo caráter comercial do 
filme, Ana Muylaert consegue transmitir, através de sua câmera e de seu roteiro, um retrato da relação de classes do nosso país, especialmente no que tange às mulheres - isso se torna evidente quando o patrão de Val, José Carlos (Lourenço Mutarelli), assedia Jéssica, em alusão à comum prática de estupros de empregadas e de escravas por seus patrões ou senhores e legitimada pelos discursos de poder do patriarcado burguês e escravocrata.

Na segunda onda feminista, as mulheres clamavam por um lugar no mercado de trabalho. No entanto, às mulheres negras e pobres esse lugar sempre foi imposto. Em “Democracia em vertigem" (2019), filme sobre o qual falarei a seguir, a diretora cita um escritor grego que diz que a democracia só funciona quando os ricos se sentem ameaçados; caso contrário, a oligarquia toma o poder. "Que horas ela volta?" trata exatamente disso, começando pelo fato de que Jéssica, mesmo com menos recursos que Fabinho, consegue passar no vestibular e ele não. O filme fala da indignação das classes privilegiadas, que sempre tiveram tudo em detrimento dos mais pobres, quando estes começam a ascender socialmente, seja pela regularização do trabalho das domésticas, seja pela política de ações afirmativas.

No final, ao descobrir que Jéssica deixou um filho em Pernambuco para estudar em São Paulo, querendo, assim como ela, dar um futuro melhor para ele, Val decide quebrar esse ciclo e trazê-lo para perto das duas, em uma conciliação final entre mãe e filha.

\section{"Mulher do pai" (2016), de Cristiane Oliveira}

O filme "Mulher do pai" (2016), dirigido e roteirizado pela gaúcha Cristiane Oliveira, conta a história de Nalu (Maria Galant), uma adolescente que vive na fronteira entre o Brasil e o Uruguai (e na fronteira entre a infância e a vida adulta), tendo que lidar com os cuidados do pai cego, Ruben (Marat Descartes), depois que sua avó morre. Como 106 na maioria dos filmes brasileiros dirigidos/roteirizados por mulheres que retratam a adolescências - tais como "Antes que o mundo acabe" (2009), de Ana Luíza Azevedo, “Desenrola" (2011), de Rosane Svartman, e "Califórnia" (2015), de Marina Person -, Mulher do pai fala sobre a descoberta sexual feminina, frustrações e idealizações típicas da idade e a relação da adolescente com os pais. Por a adolescência ser uma travessia da infância à vida adulta, a diretora revela que a escolha pela fronteira (com limites fluídos e intensa troca cultural) tem um significado simbólico. A troca entre pai e filha se dá pela pele, entre o interno e o externo, entre as fronteiras reais e aquelas que construímos para nós mesmos, o que o torna bastante singular e sensível.

A descoberta sexual da protagonista está enlaçada à sua relação com o pai, aludindo ao Complexo de Édipo, isto é, a um vínculo incestuoso. A história trata de uma mulher ausente - a mãe de Nalu -, cujo lugar acaba por ser ocupado pela protagonista. Sem autonomia, a jovem só imagina que poderá se ver livre e sair de casa (e da fronteira) com outro homem, o que Cristiane Oliveira, na conversa supracitada, relaciona com a cultura machista acentuada, típica do Rio Grande do Sul. Com a chegada de uma nova mulher, a uruguaia Rosario (Veronica Perrotta), há uma triangulação erótica, que encerra com a aceitação de Nalu, saindo da zona fronteiriça, no encontro do pai (brasileiro) com sua amante (uruguaia), mulher do pai.

\section{“Como nossos pais" (2017), de Laís Bodanzki}

“É uma coisa que tá no inconsciente coletivo, Pedro, é uma coisa que a gente não tem consciência. Os homens, eles têm que ser protagonistas, eles querem ficar no palco e eles querem as mulheres ali, na plateia, aplaudindo" (conversa entre Rosa [Maria Ribeiro] e Pedro [Felipe Rocha], no filme Como nossos pais).

Filme de 2017, estrelado por Maria Ribeiro e Clarisse Abujamra, indaga sobre o fenômeno da super-mãe, explorando os diferentes modos de maternidade: a 
protagonista, Rosa, está vivendo uma fase de conflitos pessoais e geracionais como mãe, esposa, filha e aspirante a dramaturga. A história será perpassada por questionamentos sobre a idealização da maternidade e o que se espera socialmente de uma mãe - tais como abrir mão da carreira dos sonhos em favor dos filhos, do marido e da casa e as consequências psíquicas de uma decisão dessas na vida de uma mulher.

“Não quero mais fingir que sou uma mulher que dá conta de tudo. Eu não dou conta de tudo", desabafa Rosa com o marido após ser demitida do emprego. O antropólogo Dado (Paulo Vilhena) delega a ela os cuidados da casa e das filhas, enquanto constrói sua carreira e, supostamente, a trai com uma colega de trabalho. Em meio a isso, sua mãe, Clarice - artista e libertária, aparentemente, diferente de Rosa -, revela à protagonista que está com câncer terminal e que seu pai não é o homem que a criou. Essa revelação estimula Rosa a dar uma virada em sua vida e se redescobrir como mulher, o que culmina na cena de Rosa tirando a roupa em uma avenida movimentada, representando a liberdade que sente com essa busca.

A protagonista não quer mais ser subordinada aos papéis femininos impostos pela sociedade patriarcal e enfrenta conflitos geracionais tanto com sua mãe quanto com suas filhas adolescentes, além de ter de lidar com a realidade de outro pai e com um marido egoísta que não cumpre seu papel de pai. Ann Kaplan (1995) diz que o empoderamento feminino no cinema (quando elas assumem o olhar) está, normalmente, atrelado à perda de características ditas "femininas" das personagens, não relativas à sedução, mas de bondade, humanidade e maternidade. Contudo, a diretora consegue fugir desse caminho convencional. O que resta, no final, é uma mulher livre, em paz com as outras mulheres que permeiam sua vida, porque elas, assim como Rosa, percebem que é mutuamente se apoiando que conseguem ser livres.
A diretora Laís Bodanzki constrói uma narrativa sensível com dilemas comuns a muitas mulheres da atualidade, as quais enfrentam jornada tripla de trabalho sem receber 0 devido reconhecimento, pois "não fazem mais do que sua obrigação". Convidandonos a entrar na intimidade de Rosa, por processos de identificação, Bodanzki (em conjunto com a belíssima atuação de Maria Ribeiro) desmistifica o lugar santificado atribuída à mãe.

\section{“Meu nome é Jacque" (2016), de Angela Zoé}

Nesse documentário, conhecemos Jacque, mulher transexual que vive com AIDS há mais de 20 anos. Acompanhamos sua trajetória tanto pessoal - junto com sua família e amigos - quanto como militante e representante brasileira dos direitos LGBTQIA+ na ONU. Discorrendo em uma narrativa convencional, a diretora Angela Zoé traça a vida de Jacque desde a infância, sua descoberta como mulher transgênero, passando pela maternidade e sua relação com mãe, irmãos, amigos, marido e filhos. Embora seja uma história muito individual, com trajetória bastante singular, Meu nome é Jacque evoca a necessidade de dar visibilidade à existência da comunidade trans e denunciar o preconceito intenso no Brasil - país que mais mata pessoas transgêneras no mundo.

A transgeneridade (e outros tipos de identidade de gênero que fogem à cisnormativade e ao binarismo) ainda é considerada uma patologia, constando na mais recente edição do Manual Diagnóstico e Estatístico de Transtornos Mentais (DSM-5). No filme, Jacque fala da experiência de se descobrir uma mulher trans e seguimos sua rotina por um dia, entrando em sua intimidade, seja quando ela conta sua história, de como foi apoiada pela família, de como conheceu seu marido, da adoção de seus filhos, da convivência com o HIV, de sua luta contra a discriminação na ONU e no governo (o que inclui o trabalho pela retirada da transgeneridade como 
transtorno mental de manuais diagnósticos), seja quando ela está tomando banho, em um momento mais poético e intimista do documentário.

A psicanálise elabora uma teoria da sexualidade centrada no falo, o que consiste em uma normatização da sexualidade, a partir dos complexos de Édipo e de castração. Nesse sentido, Lacan (2009, p. 30) sugere que as intervenções médicas não apagam a castração, que é simbólica; elas operam sobre a inadequação entre o sexo designado pelo Outro e o designado pelo próprio sujeito (não se trata de um problema de biologia, mas de linguagem):

Para ter acesso ao outro sexo, realmente é preciso pagar o preço, o da pequena diferença, que passa enganosamente para o real por intermédio do órgão, justamente no que ele deixa de ser tomado como tal e, ao mesmo tempo, revela o que significa ser órgão. Um órgão só é instrumento por meio disto em que todo instrumento se baseia: é que ele é um significante. É como significante que o transexual não o quer mais, e não como órgão. No que ele padece de um erro, que é justamente o erro comum. Sua paixão, a do transexual, é a loucura de querer livrar-se desse erro, o erro comum que não vê que o significante é o gozo e que o falo é apenas o significado. O transexual não quer mais ser significado como falo pelo discurso sexual, o qual, como anúncio, é impossível. Existe apenas um erro, que é querer forçar pela cirurgia o discurso sexual, que, na medida em que é impossível, é a passagem do real.

Para Freud (2011), a orientação sexual (preferência de parceirxs sexuais) e a identidade de gênero (como a pessoa se define, se homem ou mulher, cisgênero, transgênero, não-binário e outras possibilidades) não estavam necessariamente atrelados. Ainda assim, seu modelo teórico é atravessado pelo dualismo "ter ou não ter o falo". Essa noção vai de encontro à teoria da filósofa Judith Butler, que "recusa o postulado da binaridade dos sexos, expresso pela centralidade do falo como organizador único da sexualidade" (COSSI \& DUNKER, 2017, p. 4). Cossi e Dunker (2017, p. 8) observam 110 que Lacan, apesar de não confundir pênis e falo, entende a função do Édipo como a enunciação da virilidade, no homem, e da feminilização, na mulher, o que Butler chama de performance. Para a filósofa, as noções de gênero e de diferença sexual passam pela esfera psíquica, somática e social, ou seja, passam pelo domínio discursivo vigente, diferenciando-os no fato de que "gênero traduz a diferença sexual, mas a diferença sexual não se transcreve inteiramente em diferenças de gênero". Para Cossi e Dunker (2017), a ideia de diferença sexual pulsional de Butler seria compatível com a diferença sexual real de Lacan, inassimilável pela linguagem, irredutível ao corpo e ao social.

Para além da teoria, em que essa discussão não se encerra e tem avançado, o que Jacqueline Rocha Côrtes faz nesse documentário, junto com Angela Zoé, é um ato político de se fazer ser vista e escutada desde sua posição (singular, porque se trata de sua experiência e das pessoas de sua esfera social) de mulher trans no laço social.

\section{“Democracia em vertigem” (2019), de Petra Costa}

“Como lidar com a vertigem de ser lançado em um futuro que parece tão sombrio quanto nosso passado mais obscuro? O que fazer quando a máscara da civilidade cai e o que se revela é uma imagem ainda mais assustadora de nós mesmos? De onde tirar forças para caminhar entre as ruínas e começar de novo? "(monólogo final da cineasta no documentário).

Indicado ao Oscar de Melhor Documentário em 2020 (ganhando, assim, visibilidade mundial), "Democracia em vertigem" fala sobre os bastidores do golpe de 2016, que levou ao impeachment da presidenta Dilma Roussef. Em voz over, a diretora, roteirista e produtora, Petra Costa, faz um relato intimista sobre esse golpe de estado, traçando sua trajetória e remontando-o aos protestos de junho de 2013, discorrendo sobre nossa frágil democracia, relembrando os anos de ditadura militar (1964-1985) - em 
que seus pais lutaram em guerrilhas e foram presos políticos -, até o nascimento de nossa República, em um golpe das oligarquias militares, em 1889, passando pela construção de Brasília no governo JK (presidente entre 1956 e 1961).

Nunca caindo no discurso panfletário, a cineasta fala desde seu lugar de mulher sobre como foi para ela ver uma mulher ser eleita e destituída do cargo de poder mais importante do país, a "histérica louca" pintada, discursivamente, pelo patriarcado nacional, dando lugar à "bela, recatada e do lar". Andreia Almeida Campos (2016, p. 7), em A cultura do estupro como método perverso de controle nas sociedades patriarcais, afirma:

No patriarcado há uma verticalização das instâncias de poder, na qual todos, de seus patamares hierárquico, estão submetidos e subjugados ao ápice da pirâmide, ao pai, ao chefe do sexo masculino. Se esse homem durante os tempos pré-históricos era o pai da horda, o mais forte, com a evolução das organizações sociais dentro do modelo patriarcal, ele passou a ser aquele que mais detém a propriedade privada e, por conseguinte, o poder político sobre a comunidade.

Apesar de ser um relato pessoal, seus sentimentos são partilhados por todas nós que sentimos no golpe a violência da sociedade machista. Petra (nome dado em homenagem ao mentor de seus pais, assassinado por militares) nos apresenta fatos, combinando-os com relatos de sua família: privilegiada de muitas formas (branca e burguesa, por exemplo), cujos muitos membros apoiaram tanto o golpe de 1964 quanto o de 2016. Sua mãe, a jornalista e socióloga Marília Andrade, desvincula-se da esfera familiar ao conhecer Manoel Costa, pai da cineasta, e conta suas experiências na ditadura, tendo sido presa em 1968 no mesmo lugar em que Dilma seria presa e torturada 2 anos depois.

Antes de "Democracia em vertigem", Petra já havia dirigido outros filmes de caráter documental, dentre os quais "Elena" (2012), semi-autobiográfico, onde ela conta a história de perda e luto por sua irmã, Elena Costa, e as questões de saúde mental que a levaram ao suicídio, no que ela chama, em entrevista à revista Marie Claire, de "complexo de Ofélia" (em referência à personagem de Shakespeare): "um afogar nas próprias emoções no vir a ser mulher". Petra também dirige "Olmo e gaivota" (2014), que acompanha a gravidez de uma atriz de teatro e as dificuldades inerentes à gestação. Em todas as suas produções, Petra contou com uma equipe majoritariamente feminina e, para a cineasta, fazer o filme, em si, já se configurou como uma experiência política, ao notar que as mulheres no prédio do parlamento da nossa "coisa pública" eram quase ausentes. Ela fecha a entrevista afirmando:

Como fala Paulo Freire, somente os oprimidos, libertando-se, podem libertar os opressores. Isso é nossa tarefa como mulher. Lutar para habitar nossos corpos, criar nossa própria voz. O abuso do corpo da mulher (que aumentou vertiginosamente desde a última eleição), o silenciamento de sua expressão, me parece reflexo de uma terra abusada. Uma terra que segue se desfazendo em lágrimas cada vez que é subtraída em tenebrosas transações. Até que consigamos regerminar essa terra abusada, para que ela se refaça por dentro, e frutifique.

Apesar de poder ser considerado um símbolo fálico daquilo que é escolhido por poucas pessoas como de qualidade ou não, a indicação ao Oscar, em um momento de desmonte da Ancine, censura e cerca de um mês após o presidente dizer que há anos o Brasil não produz filmes de qualidade, é importante o simbolismo que esse reconhecimento traz. Em sua rede social, Petra Costa fala sobre a indicação ao prêmio tido como o mais importante do cinema:

Numa época em que a extrema direita está se espalhando como uma epidemia, esperamos que esse filme possa nos ajudar a entender como é crucial proteger nossas democracias. Está se tornando cada vez mais evidente o quanto o pessoal é político para tantos ao redor do mundo, e acredito que é por meio de histórias, linguagem e 
documentários que as civilizações começam a se curar.

\section{CONSIDERAÇÕES FINAIS}

Fazer uma pesquisa sobre as mulheres que produzem cinema no Brasil foi mais difícil do que eu havia previsto. Em vez de pesquisar através de materiais diversos, o que encontrei foi escasso, sobretudo, em fontes primárias (como breves reportagens e artigos, nenhum que se aprofundasse no tema). Comecei a me questionar sobre quantas brasileiras eram cineastas, se eram tão poucas como aparentava e, após muito procurar, produzi uma lista com mais de 100 diretoras, roteiristas e produtoras, a qual tende a crescer. A maior parte dos filmes é composta por documentários e curtas-metragem (por demandarem um orçamento menor).

Em um país que pouca importância dá para a cultura, não é surpresa, embora seja decepcionante, depararmo-nos com tamanha indiferença com essas produções, as quais falam da nossa identidade de brasileiras e de tudo o que representa ser mulher no Brasil (independentemente das nossas circunstâncias), como também engendra modos de ser, fazendo-nos refletir sobre nossos papéis socialmente impostos e como os ultrapassar. Fazer cinema é um dos passos possíveis nessa direção e, por isso, é imprescindível valorizar o cinema brasileiro feito por mulheres.

\section{REFERÊNCIAS}

ADELMAN, Miriam. Vozes, olhares e o gênero do cinema. In: FUNCK, Suzana; WIDHOLZER, Nara (Orgs.). Gênero em discursos da mídia. Florianópolis: Ed. Mulheres. Santa Cruz do Sul: EDUNISC, 2005.

AMERICAN Psychiatric Association. DSM 5: manual diagnóstico e estatístico de transtornos mentais. Porto Alegre: ARTMED, 2014.

ASTRE, Georges-Albert. 0 homem e as estrelas. In: L'Amerique des stars: I'histoire, la 114 mythologie et le rêve, v. 8, mai./jun., 1976.

BERTH, Joice. Embranquecimento e colorismo: estratégias históricas e institucionais do racismo brasileiro. 2018. Disponível em: https://medium.com/@ joiberth/embranquecimento-e-colorismo-estrat\%C3\%A9gias-hist\%C3\%B3ricas-einstitucionais-do-racismo-brasileiro-afc830581945. Acesso em: 13 jun. 2018.

BUTLER, Judith. Gender trouble: feminism and the subversion of identity. New York: Routledge, 1999.

CAMPOS, Andrea Almeida. A cultura do estupro como método perverso de controle nas sociedades patriarcais. Espaço acadêmico, UniversidadeFederal dePernambuco, v. 16, n. 183, p. 1-13, 2016.

CANTO, Vanessa Santos. O Devir-“Mulher Negra”: uma proposta ontológica e epistemológica. Lugar comum: estudos de mídia, cultura e democracia, Universidade Federal do Rio de Janeiro, n. 29, set.-dez., p. 59, 2009.

CINE KURUMIN, 6, 2017. Salvador. Disponível em <https://pt-br.facebook.com/cine. kurumin/videos/vb.1376435189330087/1463110837329188/?type=2\&theater $>$. Acesso em: 10 out. 2017.

CLASEN, Luisa. A chegada do cinema no Brasil. 2017. Disponível em: $<$ https://www. youtube.com/watch?v=bmBuPPuAjWo>. Acesso em: 20 jun. 2018.

CORSO, Diana; CORSO, Mário. A psicanálise na Terra do Nunca: ensaios sobre a fantasia. Porto Alegre: Penso, 2011.

COSSI, Rafael Kalaf; DUNKER, Christian Ingo Lenz. A diferença sexual de Butler a Lacan: gênero, espécie e família. In: Psicologia: teoria e pesquisa, v. 33, p. 1-8, 2017. COSTA, Petra. Marie Claire. Rio de Janeiro, 05 fev. 2020. Disponível em: <https:// revistamarieclaire.globo.com/Cultura/noticia/2020/02/mulheres-de-petra.html>. Acesso em: 05 fev. 2020.

DE LAURETIS, Teresa. Alice doesn't: feminism, semiotics, cinema. Indiana: Indiana 
University Press, 1984.

DE LAURETIS, Teresa. A tecnologia do gênero. In: Tendências e impasses: o feminismo como crítica da cultura. Rio de Janeiro: Rocco, 1994. pp. 206-242.

FERREIRA, Viviane. Encontros de Cinema. Itaú Cultural. 2016. Disponível em: < https:// www.youtube.com/watch?time_continue $=460 \& v=z 43 q p 9$ uhi20\&feature $=e m b$ title>. Acesso em: 19 dez. 2019.

FREUD, Sigmund. A psicogênese de um caso de homossexualidade feminina. In: Obras completas. São Paulo: Companhia das Letras, 2011.

GUARANI, Graci. Cineastas indígenas. 2018. Disponível em:https://pt-br.facebook.com/cine.kurumin/videos/ vb.1376435189330087/553373611748996/?type=2\&theater. Acesso em: 10 fev. 2020.

HORNEY, Karen. Medo da mulher. In: HORNEY, Karen. Psicologia feminina. Rio de Janeiro: Bertrand Brasil, 1991.

KAPLAN, Elizabeth Ann. A mulher e o cinema. Rio de Janeiro: Rocco, 1995.

LACAN, Jacques. $\mathbf{O}$ seminário sobre “A carta roubada”. In: LACAN, Jacques. Escritos. Rio de Janeiro: Zahar, 1998. pp. 13-66.

LACAN, Jacques. 0 seminário, livro 11: os quatro conceitos fundamentais da psicanálise. Rio de Janeiro: Zahar, 2008.

LACAN, Jacques. 0 seminário, livro 18: de um discurso que não fosse semblante. Rio de Janeiro: Zahar, 2009.

MCMAHAN, Alison. Alice Guy Blaché: lost visionary of the cinema. New York: Bloomsbury Academic, 2002.

MULVEY, Laura. Prazer visual e cinema narrativo. In: XAVIER, Ismail (Org.). A experiência do cinema. Rio de Janeiro: Graal, 2008. pp. 437-453.

OLIVEIRA, Cristiane. Pesquisa sobre cineastas brasileiras [mensagem pessoal].
Mensagem recebido por: <barbararefosco1990@gmail.com> em 07 jan. 2018.

SAFFIOTI, Heleieth. Gênero, patriarcado, violência. São Paulo: Expressão Popular/ Fundação Perseu Abramo, 2015.

SCOT, Joan. Gender: a useful category of historical analyses. In: Gender and the politics of history. Columbia University Press, 1989. 